\title{
Comparing the Effect of Boiled Anethum graveolens Seed with Oxytocin on the Duration of Labor and Pain in Iranian Women: A Randomized Clinical Trial
}

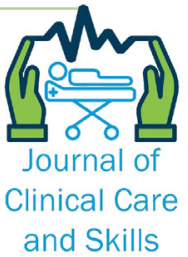

and Skills

\section{ARTICLE INFO}

\section{Article Type}

Original Research

\section{Authors}

Hekmatzadeh S.F.*1 MSc,

Aramesh Sh. ${ }^{2} M D$

Bashti S. ${ }^{1} M S c$

How to cite this article
Hekmatzadeh S.F, Aramesh Sh, Bas-
hti S. Comparing the Effect of Boiled
Anethum graveolens Seed with Ox-
ytocin on the Duration of Labor and
Pain in Iranian Women: A Randomi-
zed Clinical Trial. Journal of Clinical
Care and Skills. 2020;1(4):165-170.

${ }^{1}$ Medicinal Plant Research Center, Yasuj University of Medical Sciences, Yasuj, Iran ${ }^{2}$ Gynecology \& Obstetrics Department, Yasuj University of Medical Sciences, Yasuj, Iran

\section{*Correspondence}

Address: Medicinal Plant Research Center, Yasuj University of Medical Sciences, Yasuj, Iran. Postal Code: 7591718874.

Phone: +98 (74) 33230290

Fax: +98 (74) 33230290

sf.hekmatzadeh@yahoo.com

\section{Article History}

Received: October 21, 2019

Accepted: January 06, 2020

ePublished: October 01, 2020

\section{A B S T R A C T}

Aims To advance birth and avoid prolonged labor, oxytocin is routinely used globally. However there are a number of side-effects in this therapy. The aim of this study was to evaluate the effect of boiled Anethum graveolens seed on the duration and intensity of labor pain in comparison to oxytocin.

Materials \& Methods This randomized clinical trial was conducted on 88 pregnant women admitted to the birth center of Imam Sajjad, Yasuj hospital, Iran in 2015-2016. The subjects were selected by purposive sampling method and randomly allocated to Anethum graveolens $(\mathrm{n}=41)$ and oxytocin $(\mathrm{n}=47)$ groups. In Anethum graveolens group, 10gr of Anethum graveolens seed was boiled in $100 \mathrm{ml}$ of water for 10 minutes and, after filtration, was given to participants to swallow at the start of active labor. In oxytocin group, 10 units of oxytocin in $1000 \mathrm{ml}$ of Ringer's solution was diluted and administered by infusion when the contractions were established. Data were analyzed by SPSS 21 software using chi square, Mann-Whitney $\mathrm{U}$ and independent $\mathrm{t}$ test.

Findings Labor was shorter in the first, second and third stages in Anethum graveolens group compared to oxytocin group. However there was a significant difference only in the 1st stage of labor $(\mathrm{p}<0.001)$. The dilatation and effacement scores improved in Anethum graveolens group than the oxytocin group $(\mathrm{p}<0.05)$ at one, two, three, and four hours of continuous intervention.

Conclusion Using boiled Anethum graveolens seed can be effective in reducing the length of labor and improving dilatation and effacement during birth.

Keywords Anethum graveolens; Oxytocin; Labor; Pain

\section{I T A T I O N L I N K S}

[1] The effect of boiled dill (Anethum graveolens) seeds on the long active phase and labor pain intensity [2] Epidural analgesia in association with duration of labor and mode of delivery: a quantitative review [3] How long is too long: Does a prolonged second stage of labor in nulliparous women affect maternal and neonatal outcomes [4] Duration of the second stage of labor in multiparous women: maternal and neonatal outcomes [5] Comparison between two oxytocin regimen for induction of labor [6] Gestational diabetes and neonatal macrosomia in the polycystic ovary syndrome [7] Effect of dill (Anethum graveolens Linn.) seed on uterus contractions pattern in active phase of labor [8] Use of herbal medicines among pregnant women attending family health centers in Alexandria [9] Water-soluble constituents of dill [10] A preliminary study of the effect of essential oils on skeletal and smooth muscle in vitro [11] A randomized clinical trial of the efficacy of applying a simple protocol of boiled Anethum Graveolens seeds on pain intensity and duration of labor stages [12] An investigation of effectiveness of oral dill extracts on postpartum hemorrhage [13] Motherisk-PUQE (pregnancyunique quantification of emesis and nausea) scoring system for nausea and vomiting of pregnancy [14] Socioeconomic status and mortality after acute myocardial infarction: a study from Iran [15] Does Mid-trimester Cervical Length $\geq 25$ mm Predict Preterm Birth in High-Risk Women [16] Phenotypic spectrum of polycystic ovary syndrome: clinical and biochemical characterization of the three major clinical subgroups [17] Pelvic floor dysfunction and polycystic ovary syndrome [18] Anti-inflammatory properties of human milk [19] Textbook of public health [20] Juniperi fructus is the dried berry-like cones of Juniperus communis [21] The effect of 12 weeks Anethum graveolens (dill) on metabolic markers in patients with metabolic syndrome; a randomized double blind controlled trial [22] Testosterone and the free androgen index 


\section{Introduction}

Prolonged labor causes $8 \%$ of maternal mortality in developing countries. The World Health Organization (WHO) figures show that about $3 \%$ of children suffer from moderate to severe birth asphyxia caused by prolonged delivery. Apgar scores in babies in NICU after prolonged labor are lower. $3.27-9.7 \%$ of deaths in women over 15 years old are caused by prolonged labor [1-4]. Prolonged labor leads to increased infection rates in mothers, and further poor maternal such as psychological distress in mothers and increased caesarian births [5] resulting in increased length of stay and cost of hospitalization.

To advance birth and avoid prolonged labor, oxytocin is routinely used globally. However there are a number of side-effects in this therapy for mother and infant. Oxytocin causes jaundice and elevated bilirubin in infants ${ }^{[6]}$ and in high doses, causes strong and long-lasting contractions. Such contractions can increase the mother's pain and cause loss of oxygen to the fetus and subsequent fetal distress; further complications cause uterine rupture, hypotension, bradycardia and headaches. Authors argue that there is a need for safer alternatives to replace oxytocin $[6$, 7]. One of these alternatives may be herbal therapies. The incidence of herb therapy using Anethum graveolens during pregnancy is $56 \%$ in the United Kingdom, $48 \%$ in Italy and $38 \%$ in Norway [8]. The chemical composition of Anethum graveolens seed is tannin, a resin and an essential oil extracted from limonene, ketone, carvone. Most polyphenols are tannins, which contain contraction properties [9]. One study has shown that Anethole causes smooth muscle contraction which may be due to increased calcium levels [10],

Recent studies show that Anethum graveolens may potentially be a suitable alternative to oxytocin. Hekmatzadeh et al. have shown that boiled Anethum graveolens seed shortens delivery in the women $[1,11]$. According to Mahdavian et al., Anethum graveolens seed extract compared to intramuscular administration of oxytocin immediately after delivery causes more uterine contractions and reduces bleeding after delivery in the women [12]. Koren et al. have shown labor induction in mice by the administration of Anethum graveolens extract to be more potent than oxytocin [13]. In Ebrahimzadeh et al. study, Anethum graveolens seed also shortened the first stage of labor in women [7]. Only one study has compared the effects of Anethum graveolens seed and oxytocin on labor pain and duration in the women. They reported that the mean duration of active phase, second and third stages of labor were significantly lower in the Anethum graveolens group. $0.018 \mathrm{~g} / \mathrm{kg}$ of Anethum graveolens seeds and a teaspoon full of sugar was dissolved into $250 \mathrm{ml}$ of boiling water and brewed for about 10 minutes. The dose was determined by results from a previous study into the effectiveness of Anethum graveolens on postpartum hemorrhage [12]. But, we used from previous study about Anethum graveolens on labor duration and pain intensity ${ }^{[1,11]}$.

Therefore the aim of this study was to evaluate the effect of boiled Anethum graveolens seed on the duration and intensity of labor pain in comparison to oxytocin.

\section{Materials and Methods}

This single blinded randomized clinical trial was conducted on pregnant women admitted to the birth center of Imam Sajjad, Yasuj hospital, Iran in 20152016. Allocation to Anethum graveolens (new protocol) or oxytocin groups (normal protocol) was done by "table of random numbers" method. Sample size was calculated using the study of Ebrahimzadeh et al. [7], and at least 40 people were estimated for each group.

The inclusion criteria were spontaneous and real uterine contractions (active phase), maternal age 1835 years, estimated fetal weight 4000-2500grams, first or second parity, no indication for cesarean delivery, lack of medical condition or history hospitalizations for mental illness, lack of addiction or smoking, and lack of problems in the current pregnancy such as preeclampsia, bleeding and infection, normal BMI. Exclusion criteria included the presence of vaginal bleeding and cesarean delivery. 100 pregnant women admitted to the birth center who met the inclusion criteria were selected by purposive sampling method and randomly allocated to the Anethum graveolens $(n=50)$ and oxytocin $(n=50)$ groups. 3 people in oxytocin group due to caesarean and 9 people in Anethum graveolens group due to use oxytocin for prolonged the first stage of labor excluded the study, therefore 47 people in oxytocin group and 41 people in Anethum graveolens group were studied.

After the approval of the ethics committee of Yasuj medical university of sciences, Iran, this study was conducted. At first, the purpose of the study explained to all participants and written consent was received from them who were advised that they could withdraw at any time they wish during the study. Anethum graveolens grows to $30-100 \mathrm{~cm}$ globally and may be wild or farmed. In this study, wild Anethum graveolens seed in the areas around Yasuj, Iran were collected (Figure 1). The seed collected were identified by a botanist (Dr Amin Salehi, Agronomy Department, Yasuj University, Yasuj, Iran) and a herbarium sample stored in an appropriate institution.

Ten grams of Anethum graveolens seed were boiled for 10 minutes in $100 \mathrm{ml}$ of water. After filtration of the solution, participants were given this solution once orally at the beginning of the active phase of labor. This dosage regimen was determined by referring to previous clinical trials testing the effects of similar boiled Anethum graveolens seed for the 
same indication $[1,11]$.

10 IU of oxytocin in $1000 \mathrm{ml}$ of Ringer solution was infused intravenously to stimulate uterine contractions. The infusion started at five drops and then five drops were added every 15 minutes were administered every 60-90 seconds, until three contractions were established 45-60 seconds apart.

Fetal heart rate (FHR) in both groups was recorded every 15 minutes. A non-stress test (NST) 20-minute tape was obtained from all participants during labor. Each hour, vaginal examination and vital signs were assessed. Pain by visual analogue scale (VAS) and duration of uterine contractions were measured by touching the fundus. Vomiting or other gastrointestinal symptoms were recorded.

Demographic and baseline reproductive data were collected including: age, occupation, gravid (number of pregnancy), abortion, rupture of membrane, birth weight, BMI, and socioeconomic status. The years of formal education were used as a measure of socioeconomic status (categorized into five levels: no education, first level ( 1 to 5 years), second level (6-9 years), third level (10-12 years) and fourth level (more than 12 years). Studies in Iran showed that education can be a good proxy measure for socioeconomic status for Iranians [14].

Outcome of measures included labor pain intensity, dilatation and effacement scores, duration of labor, vital signs, Apgar score and FHR.

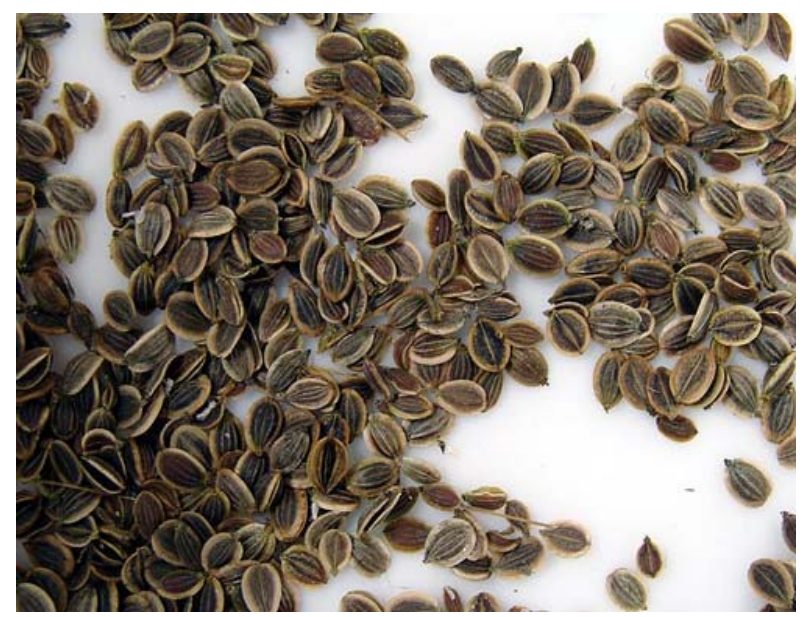

Figure 1) Anethum graveolens seeds

Visual analogue scale (VAS): The VAS using a $10^{-} \mathrm{cm}$ line represented the continuum of the participant's opinion of the degree of pain. One extremity of the line represented "unbearable pain," and the other extremity represented "no pain at all." The participants were asked to rate the degree of pain by making a mark on the line. Validity and reliability was confirmed.

Dilatation and effacement scores: Each hour, vaginal examination was assessed. Effacement means that the cervix stretches and gets thinner. Dilatation means that the cervix opens.
Hekmatzadeh S.F. et al. Duration of labor: Duration of labor was considered as three stages: $1^{\text {st }}$ stage when the cervix opens (in this study the start of active phase of labor) to $10 \mathrm{~cm}$ dilatation; $2^{\text {nd }}$ stage when the baby moves down through the vagina to be born; $3^{\text {rd }}$ stage when the placenta (after birth) is delivered. The length of above stages was timed.

Vital signs: Each hour, vital signs were assessed.

Apgar score: Apgar score evaluates the newborn's physical condition to see if there's an immediate need for extra medical or emergency care. This measure includes appearance, pulse, grimace, activity and respiration. The Apgar test is usually given to a baby twice: once at 1 minute after birth, and again at 5 minutes after birth.

FHR: Fetal heart rate (FHR) in both groups was recorded every 15 minutes.

Data were analyzed by SPSS 21 software using chi square, Mann-Whitney U (for qualitative variables) and independent $t$ test (for quantitative variables).

\section{Findings}

There was no significant difference between the two groups in terms of qualitative and quantitative demographic variables (Tables 1 and 2).

Duration of labor in the first, second, and third phase were shorter in the boiled Anethum graveolens seed group compared to the oxytocin group. However, the difference between the two groups was significant only in the first stage of labor (Table 3).

There was no statistically significant difference between the two groups in terms of intensity of pain at the end of the first $(p=0.18)$, second $(p=0.06)$, third $(\mathrm{p}=0.08)$, and fourth hour of labor $(\mathrm{p}=0.40)$. But, dilatation and effacement in the boiled Anethum graveolens seed group was better after the first, second, third and fourth hours of labor compared to the oxytocin group $(\mathrm{p}<0.05$; Table 4$)$.

Also there was no significant difference between the two groups regarding characteristics of mother and fetus (Table 5).

Table 1) The comparison of statistical mean of quantitative demographic variables between Anethum graveolens $\underline{(n=41) \text { and oxytocin }(\mathrm{n}=47) \text { groups }}$

\begin{tabular}{|c|c|c|c|}
\hline Variables & $\begin{array}{l}\text { Anethum } \\
\text { graveolens } \\
\text { group }\end{array}$ & Oxytocin group & P. value \\
\hline $\begin{array}{l}\text { Age (years } \\
\text { old) }\end{array}$ & $23.53 \pm 3.65$ & $24.59 \pm 3.58$ & 0.21 \\
\hline Gravity & $1.26 \pm 0.44$ & $1.47 \pm 0.54$ & 0.06 \\
\hline $\begin{array}{l}\text { Gestational } \\
\text { age (weeks) }\end{array}$ & $38.62 \pm 1.59$ & $38.63 \pm 1.58$ & 0.97 \\
\hline $\begin{array}{l}\text { BMI } \\
(\mathrm{kg} / \mathrm{m} 2)\end{array}$ & $27.26 \pm 7.06$ & $28.35 \pm 4.28$ & 0.06 \\
\hline $\begin{array}{l}\text { Birth } \\
\text { weight (g) }\end{array}$ & $3165.85 \pm 299.65$ & $3157.46 \pm 351.60$ & 0.90 \\
\hline \multicolumn{4}{|l|}{ Apgar score } \\
\hline 1 minute & $10.97 \pm 2.67$ & $8.97 \pm 0.14$ & 0.2 \\
\hline 5 minute & $10.00 \pm 0.01$ & $10.00 \pm 0.01$ & - \\
\hline
\end{tabular}


Comparing the Effect of Boiled Anethum graveolens Seed with Oxytocin ...

Table 2) The comparison of distribution of absolute and relative frequency of demographic qualitative variables between Anethum graveolens $(n=41)$ and oxytocin $(n=47)$ groups (the numbers in parentheses are percentages)

\begin{tabular}{|c|c|c|c|}
\hline Variables & $\begin{array}{c}\text { Anethum } \\
\text { graveolens } \\
\text { group }\end{array}$ & $\begin{array}{l}\text { Oxytocin } \\
\text { group }\end{array}$ & P. value \\
\hline \multicolumn{4}{|l|}{ Education } \\
\hline $\begin{array}{l}\text { Guidance } \\
\text { school or less }\end{array}$ & $16(39.0)$ & $13(27.7)$ & \multirow{3}{*}{0.27} \\
\hline $\begin{array}{l}\text { Completed } \\
\text { high school }\end{array}$ & $21(51.2)$ & $26(55.3)$ & \\
\hline College & $4(9.8)$ & $8(17.0)$ & \\
\hline \multicolumn{4}{|l|}{ Occupation } \\
\hline Housewife & $40(97.6)$ & $44(93.6)$ & \multirow{2}{*}{0.17} \\
\hline Employment & $1(2.4)$ & $3(6.4)$ & \\
\hline \multicolumn{4}{|l|}{ Abortion } \\
\hline Yes & $1(2.4)$ & $1(2.1)$ & \multirow{2}{*}{0.8} \\
\hline No & $40(97.6)$ & $46(97.9)$ & \\
\hline \multicolumn{4}{|c|}{ Rupture of membrane } \\
\hline Spontaneous & $18(43.9)$ & $14(29.8)$ & \multirow{2}{*}{0.17} \\
\hline Amniotomy & $23(56.1)$ & $33(70.2)$ & \\
\hline
\end{tabular}

Table 3) The comparison of mean of duration in three stages of labor between two study groups

\begin{tabular}{lccc}
\hline \multicolumn{1}{c}{ Variables } & $\begin{array}{c}\text { Anethum } \\
\text { graveolens } \\
\text { group }\end{array}$ & $\begin{array}{c}\text { Oxytocin } \\
\text { group }\end{array}$ & P. value \\
\hline $\begin{array}{l}\text { Duration of first } \\
\text { stage (hours) }\end{array}$ & $3.15 \pm 1.12$ & $4.38 \pm 1.15$ & 0.001 \\
$\begin{array}{l}\text { Duration of } \\
\text { second stage } \\
\text { (minutes) }\end{array}$ & $24.84 \pm 13.33$ & $25.67 \pm 14.89$ & 0.78 \\
$\begin{array}{l}\text { Duration of third } \\
\text { stage (minutes) }\end{array}$ & $6.41 \pm 2.61$ & $7.27 \pm 2.37$ & 0.10 \\
\hline
\end{tabular}

Table 4) The comparison of mean of characteristics of labor between two study groups

\begin{tabular}{lccc}
\hline \multicolumn{1}{c}{ Variables } & $\begin{array}{c}\text { Anethum } \\
\text { graveolens } \\
\text { group }\end{array}$ & $\begin{array}{c}\text { Oxytocin } \\
\text { group }\end{array}$ & P. value \\
\hline Intensity of pain & & & \\
Before & $8.00 \pm 1.58$ & $7.70 \pm 1.61$ & 0.38 \\
One hour after & $8.24 \pm 1.52$ & $8.70 \pm 1.66$ & 0.18 \\
Two hour after & $9.19 \pm 1.22$ & $9.68 \pm 1.04$ & 0.06 \\
Three hour after & $9.40 \pm 0.98$ & $9.80 \pm 0.74$ & 0.08 \\
Four hour after & $10.00 \pm 0.01$ & $9.97 \pm 0.16$ & 0.4 \\
Dilatation (cm) & & & \\
Before & $3.48 \pm 0.55$ & $3.51 \pm 0.50$ & 0.8 \\
One hour after & $5.00 \pm 0.83$ & $4.72 \pm 0.68$ & 0.02 \\
Two hour after & $6.90 \pm 1.17$ & $6.02 \pm 1.09$ & $<0.001$ \\
Three hour after & $8.35 \pm 1.37$ & $7.21 \pm 1.34$ & $<0.001$ \\
Four hour after & $9.16 \pm 0.04$ & $8.40 \pm 1.44$ & 0.02 \\
Effacement (\%) & & & \\
Before & $49.26 \pm 12.32$ & $53.61 \pm 10.91$ & 0.08 \\
One hour after & $60.36 \pm 8.32$ & $57.55 \pm 8.84$ & 0.01 \\
Two hour after & $73.41 \pm 9.96$ & $65.00 \pm 9.89$ & $<0.001$ \\
Three hour after & $84.72 \pm 12.46$ & $72.97 \pm 15.17$ & $<0.001$ \\
Four hour after & $91.25 \pm 11.53$ & $85.50 \pm 12.59$ & 0.05 \\
\hline
\end{tabular}

Table 5) The comparison of mean of characteristics of mother and fetus in two study groups

\begin{tabular}{|c|c|c|c|}
\hline Variables & $\begin{array}{c}\text { Anethum } \\
\text { graveolens } \\
\text { group }\end{array}$ & $\begin{array}{l}\text { Oxytocin } \\
\text { group }\end{array}$ & P. value \\
\hline \multicolumn{4}{|c|}{ Systolic blood pressure (mm Hg) } \\
\hline Before & $110.48 \pm 7.39$ & $109.78 \pm 7.65$ & 0.66 \\
\hline One hour after & $110.48 \pm 7.39$ & $109.57 \pm 7.50$ & 0.56 \\
\hline $\begin{array}{l}\text { Two hour } \\
\text { after }\end{array}$ & $108.09 \pm 16.92$ & $109.36 \pm 7.63$ & 0.64 \\
\hline $\begin{array}{l}\text { Three hour } \\
\text { after }\end{array}$ & $108.16 \pm 17.77$ & $109.34 \pm 8.00$ & 0.68 \\
\hline $\begin{array}{l}\text { Four hour } \\
\text { after }\end{array}$ & $108.41 \pm 21.81$ & $108.78 \pm 7.48$ & 0.92 \\
\hline \multicolumn{4}{|c|}{ Diastolic blood pressure (mm Hg) } \\
\hline Before & $69.02 \pm 6.63$ & $70.21 \pm 7.06$ & 0.42 \\
\hline One hour after & $69.51 \pm 6.30$ & $70.21 \pm 6.75$ & 0.61 \\
\hline $\begin{array}{l}\text { Two hour } \\
\text { after }\end{array}$ & $69.51 \pm 4.97$ & $70.00 \pm 6.25$ & 0.69 \\
\hline $\begin{array}{l}\text { Three hour } \\
\text { after }\end{array}$ & $70.81 \pm 5.46$ & $70.00 \pm 6.32$ & 0.53 \\
\hline $\begin{array}{l}\text { Four hour } \\
\text { after }\end{array}$ & $72.50 \pm 6.07$ & $70.00 \pm 6.40$ & 0.12 \\
\hline \multicolumn{4}{|c|}{ Temperature $\left({ }^{\circ} \mathrm{C}\right)$} \\
\hline Before & $36.62 \pm 0.33$ & $36.58 \pm 0.23$ & 0.54 \\
\hline One hour after & $36.62 \pm 0.33$ & $36.58 \pm 0.23$ & 0.43 \\
\hline $\begin{array}{l}\text { Two hour } \\
\text { after }\end{array}$ & $36.62 \pm 0.34$ & $36.59 \pm 0.23$ & 0.22 \\
\hline $\begin{array}{l}\text { Three hour } \\
\text { after }\end{array}$ & $36.64 \pm 0.34$ & $36.59 \pm 0.23$ & 0.86 \\
\hline $\begin{array}{l}\text { Four hour } \\
\text { after }\end{array}$ & $36.68 \pm 0.31$ & $36.60 \pm 0.34$ & 0.45 \\
\hline \multicolumn{4}{|l|}{ Pulse rate } \\
\hline Before & $73.90 \pm 7.37$ & $75.36 \pm 8.10$ & 0.40 \\
\hline One hour after & $73.90 \pm 7.37$ & $75.40 \pm 8.13$ & 0.61 \\
\hline $\begin{array}{l}\text { Two hour } \\
\text { after }\end{array}$ & $73.90 \pm 7.37$ & $75.40 \pm 8.14$ & 0.52 \\
\hline $\begin{array}{l}\text { Three hour } \\
\text { after }\end{array}$ & $74.00 \pm 7.42$ & $75.43 \pm 7.74$ & 0.32 \\
\hline $\begin{array}{l}\text { Four hour } \\
\text { after }\end{array}$ & $67.42 \pm 14.45$ & $76.39 \pm 7.98$ & 0.41 \\
\hline \multicolumn{4}{|c|}{ Respiratory rate } \\
\hline Before & $17.43 \pm 1.73$ & $17.23 \pm 1.63$ & 0.31 \\
\hline One hour after & $17.51 \pm 1.74$ & $17.27 \pm 1.76$ & 0.41 \\
\hline $\begin{array}{l}\text { Two hour } \\
\text { after }\end{array}$ & $17.51 \pm 1.81$ & $17.29 \pm 1.80$ & 0.59 \\
\hline $\begin{array}{l}\text { Three hour } \\
\text { after }\end{array}$ & $17.89 \pm 1.92$ & $17.39 \pm 1.74$ & 0.65 \\
\hline $\begin{array}{l}\text { Four hour } \\
\text { after }\end{array}$ & $18.29 \pm 2.07$ & $17.55 \pm 1.02$ & 0.71 \\
\hline \multicolumn{4}{|l|}{ FHR } \\
\hline Before & $139.390 \pm 4.37$ & $139.68 \pm 4.69$ & 0.76 \\
\hline One hour after & $138.68 \pm 4.40$ & $140.10 \pm 4.29$ & 0.12 \\
\hline $\begin{array}{l}\text { Two hour } \\
\text { after }\end{array}$ & $139.75 \pm 4.48$ & $138.46 \pm 15.39$ & 0.60 \\
\hline $\begin{array}{l}\text { Three hour } \\
\text { after }\end{array}$ & $141.45 \pm 4.14$ & $140.82 \pm 4.56$ & 0.51 \\
\hline $\begin{array}{l}\text { Four hour } \\
\text { after }\end{array}$ & $139.87 \pm 1.32$ & $140.45 \pm 1.21$ & 0.49 \\
\hline
\end{tabular}

\section{Discussion}

Oxytocin is used as first-line treatment in ineffective uterine contractions during birth, but it is associated 
with numerous side effects $[6,15,16]$. The use of herbal medicines in recent years has become increasingly popular. Repeated surveys by the World Health Organization (WHO) show that $80 \%$ women globally use herbal remedies: $33 \%$ in United States, $70 \%$ in New Zealand and $71.5 \%$ in Iran [17-19]. While studies into Anethum graveolens seed has shown that labor length and pain may be shortened using this herb, no study on its effects in labor and postpartum compared to oxytocin has been performed. Results of this study showed that duration of labor in the first, second and third stages in the boiled Anethum graveolens seed group were shorter than the oxytocin group. Dilatation and effacement in the boiled Anethum graveolens seed group was better after the first, second, third and fourth stages of labor compared to the oxytocin group $(\mathrm{p}<0.05)$.

Better scores of dilatation and effacement in the boiled Anethum graveolens seed group confirmed that Anethum graveolens seed improved labor progress. Ebrahimzadeh et al. evaluated the effect of Anethum graveolens seed on uterine contractions during the active phase of birth and reported that the number of contractions in Anethum graveolens seed group significantly improved compared to the control group and the herb reduced the duration of the first phase of labor [7]. Mahdavian et al. study showed that using Anethum graveolens seed extract immediately after delivery increased muscle contractions of the uterus and reduced bleeding after childbirth compared to oxytocin [12]. Lis-Balchin et al. reported that the Anethum graveolen seed has contraction effects on the myometrium and has the same role in uterine contractions [10]. Results of a study on Juniperi fructus showed that this herb has contractive effects on uterine because of limonene in it ${ }^{20]}$. Other studies have also reported that Anethole due to increased levels of calcium leads to contraction [10].

Based on our findings there are no statistically significant difference in pain intensity between the two groups in the active phase of labor. In other words, boiled Anethum graveolens does not affect mother's expressed pain. Hekmatzadeh et al. have also shown that pain intensity difference between the two groups was not statistically significant [11].

It should be noted in this study compared to previous studies, no adverse maternal and neonatal outcomes were observed after boiled Anethum graveolens ${ }^{[11,21]}$. This is compared to the use of synthetic drugs such as atropine and hyoscine, where side effects such as bradycardia or tachycardia are expected [22].

One of the strengths of this study is that there are no statistically significant differences in demographic characteristics and pregnancy experience between the two intervention groups for control of the placebo effect. After four hours of admission, all participants had their vital signs recorded along with Apgar score and fetal heart rate at birth to evaluate maternal and neonatal side effects. There were no significant differences between two groups.

Similar to our study, safety of Anethum graveolens in Mansouri et al.study, assessed by physical examination, vital signs, and various laboratory measurements. There were no changes in clinical laboratory assessment including liver enzymes, total bilirubin, albumin, creatinine, and electrolytes during treatment. Moreover, no significant differences were observed in the safety parameters including vital signs, results of physical examination and hematologic tests in both groups [21].

This is one of two human studies into the effects of boiled Anethum graveolens seed effect on pain intensity and duration of labor stages compared to oxytocin. Larger studies might be required to prove the efficacy and safety of administration of boiled Anethum graveolens seed on stages of and pain in labor.

While intra rater intervention was high and consequently reduced error as data extraction was performed by a single researcher, this did not completely rule out the possibility of bias. The participants were recruited from a public hospital; therefore result reduced the generalizability. It also expressed there were differences between manners of participants' talking about their severity of labor pain because mental conditions related to pain can effect on talking about severity of pain.

\section{Conclusion}

Ingestion of boiled Anethum graveolens seed results in shorter duration of labor and improves dilatation and effacement scores compared to the administration of oxytocin. Therefor this herb could be used instead of oxytocin in order to reduce oxytocin related adverse maternal and fetal outcomes and halt the increasing elective cesarean.

Acknowledgements: The authors thank and appreciate the cooperation and financial support of the Yasuj University of Medical Sciences.

Ethical Permission: Ethical approval was taken from the Yasuj University of Medical Sciences Ethics Committee, and written informed consent was taken from each participant. IRCT Number is IRCT201607177065N2.

Conflict of Interests: There is no conflict interests. Authors' Contribution: Hekmatzadeh SF. (First author), Introduction author/ Methodologist/ Original researcher/ Statistical analyst/ Discussion author (50\%); Aramesh S. (Second author), Introduction author/ Methodologist/ Original researcher/ Discussion author (30\%); Bashti S. (Third author), Introduction author/ Discussion author (20\%)

Funding: This study was performed by funding support of Yasuj University of Medical Sciences. 


\section{References}

1- Hekmatzadeh SF, Mirmolaei ST, Hosseini N. The effect of boiled dill (Anethum graveolens) seeds on the long active phase and labor pain intensity. Armaghan-e-Danesh. 2012;17(1):50-9. [Persian]

2- Zhang J, Klebanoff MA, DerSimonian R. Epidural analgesia in association with duration of labor and mode of delivery: a quantitative review. Am J Obstet Gynecol. 1999;180(4):970-7.

3- Cheng YW, Hopkins LM, Caughey AB. How long is too long: Does a prolonged second stage of labor in nulliparous women affect maternal and neonatal outcomes? Am J Obstet Gynecol. 2004;191(3):933-8.

4- Cheng YW, Hopkins LM, Laros RK, Jr., Caughey AB. Duration of the second stage of labor in multiparous women: maternal and neonatal outcomes. Am J Obstet Gynecol. 2007;196(6):585.e1-6.

5- Parashi S, Kashanian M, Bazzaz Banaei N. Comparison between two oxytocin regimen for induction of labor. Feyz. 2005;9(2):6-10. [Persian]

6- Wortsman J, de Angeles S, Futterweit W, Singh KB, Kaufmann RC. Gestational diabetes and neonatal macrosomia in the polycystic ovary syndrome. J Reprod Med. 1991;36(9):659-61.

7- Ebrahimzadeh Zagami S, Golmakani N, Kabirian M, Shakeri MT. Effect of dill (Anethum graveolens Linn.) seed on uterus contractions pattern in active phase of labor. Indian J Trad Knowledge. 2012;11(4):602-6.

8- Orief YI, Farghaly NF, Ibrahim MIA. Use of herbal medicines among pregnant women attending family health centers in Alexandria. Middle East Fertil Soc J. 2014;19(1):42-50.

9- Ishikawa T, Kudo M, Kitajima J. Watersoluble constituents of dill. Chem Pharm Bull. 2002;50(4):501-7.

10- Lis-Balchin M, Hart S. A preliminary study of the effect of essential oils on skeletal and smooth muscle in vitro. J Ethnopharmacol. 1997;58(3):183-7.

11- Hekmatzadeh SF, Bazarganipour F, Malekzadeh J, Goodarzi F, Aramesh S. A randomized clinical trial of the efficacy of applying a simple protocol of boiled Anethum Graveolens seeds on pain intensity and duration of labor stages. Complement Ther Med. 2014;22(6):970-6.
12- Mahdavian M, Golmakani N, Mansoori A, Hosseinzadeh $\mathrm{H}$, Afzalaghaei M. An investigation of effectiveness of oral dill extracts on postpartum hemorrhage. Iran J Obstet Gynecol Infertil. 2001;4(7-8):19-26. [Persian]

13- Koren G, Boskovic R, Hard M, Maltepe C, Navioz Y, Einarson A. Motherisk-PUQE (pregnancy-unique quantification of emesis and nausea) scoring system for nausea and vomiting of pregnancy. Am J Obstet Gynecol. 2002;186(5 Suppl Understanding):S228-31.

14- Donyavi T, Naieni KH, Nedjat S, Vahdaninia M, Najafi M, Montazeri A. Socioeconomic status and mortality after acute myocardial infarction: a study from Iran. Int J Equity Health. 2011;10:9.

15- Owen J, Szychowski JM, Hankins G, Iams JD, Sheffield JS, Perez-Delboy A, et al. Does Mid-trimester Cervical Length $\geq 25 \mathrm{~mm}$ Predict Preterm Birth in High-Risk Women? Am J Obstet Gynecol. 2010;203(4):393.e1-5.

16- Chang WY, Knochenhauer ES, Bartolucci AA, Azziz R. Phenotypic spectrum of polycystic ovary syndrome: clinical and biochemical characterization of the three major clinical subgroups. Fertil Steril. 2005;83(6):1717-23.

17- Taghavi SA, Bazarganipour F, Allan H, Khashavi Z, Reisi $\mathrm{N}$, Dosha N, et al. Pelvic floor dysfunction and polycystic ovary syndrome. Hum Fertil. 2017;20(4):262-7.

18- Goldman AS, Thorpe LW, Goldblum RM, Hanson LA. Anti-inflammatory properties of human milk. Acta Paediatr Scand. 1986;75(5):689-95.

19- Hatami H, Seyednozadi M, Razavi SM, Majlesi F, Parizade SMJ, Eftekhar Ardabili H. Textbook of public health. Volume 3. Tehran: Arjmand; 2006. [Persian]

20- Committee for Veterinary Medicinal Products. Juniperi fructus is the dried berry-like cones of Juniperus communis. London: The European Agency for the Evaluation of Medicinal Products; 1999 Mar. Report No. EMEA/MRL/562-99-FINAL.

21- Mansouri M, Nayebi N, Keshtkar A, Hasani-Ranjbar S, Taheri E, Larijani B. The effect of 12 weeks Anethum graveolens (dill) on metabolic markers in patients with metabolic syndrome; a randomized double blind controlled trial. Daru. 2012;20(1):47.

22- Vankrieken L. Testosterone and the free androgen index. Los Angeles, CA: Diagnostic Products Corporation; 1997. 